\title{
Vibration Control in Quarter-Car Model with Magnetorheological (MR) Dampers Using Bingham Model
}

\section{Sharma $\mathbf{S}^{*}$}

Department of Mechanical Engineering, Aligarh Muslim University, India

\begin{abstract}
A semi-active suspension system using Magnetorheological (MR) damper overcomes all the inherent limits of passive and active suspension systems and combines the advantages of both. This paper gives a concise introduction about the suspension system of passenger vehicle which is presented along with the analysis of semiactive suspension system using MR dampers based on Bingham model. Magneto rheological (MR) dampers are filled with magnetorheological fluids whose properties can be controlled by applying voltage signal. To further prove the statement, a quarter car models with two degrees of freedom has been used for modelling the suspension system, the sprung mass acceleration of passive suspension system has been compared with the semi-active suspension system using Bingham model for MR damper. Simulink/MATLAB is used to carry out the simulation. The results drawn show that the semi-active suspension system performed better than the passive suspension system in terms of vehicle stability.
\end{abstract}

Keywords: Magneto rheological damper; Electro rheological damper; Vehicle; Suspension

\section{Introduction}

The vehicle suspension system provides relative motion between the vehicle body and wheels. Suspension system consists of dampers, shock'absorbers, springs and linkages which'connect the vehicle to'its wheels. The springs andadamper are mounted in'parallel betweenethe vehicle body and wheels. The spring stores the mechanical energy and thus allows'the wheel to move relative to'the vehicle body when the wheel undergoes various road profiles. The spring stores the potential energy which'is transformed into kinetic energy of the vehicle body which is dissipated by the damper. The vehicle suspension system aims on the vehicle stability and ride comfort.

The basic tasks of automotive suspension on a vehicle are as follows:

1. To isolate the vehicle from road turbulence.

2. To make better road holding.

3. To sustain the static weight of vehicle [1].

Suspension systems are categorized as follows:-

- Passive'suspension system

- Semi-active suspension system

- Active'suspension system

A passiveesuspension system uses conventional oil dampers and is reliable, simple and cheap. The tuning of the conventional passive dampers involves the physical change of their valves. The passive suspension systems are not able to function satisfactorily in a broad range of road states because the setting is kept fixed during their lifetime. Active'and semi-active suspensions contain control systems that force the system to achieve optimized conditions. Active suspensions make use of electro-hydraulic actuators which gives a required control force, calculated by the system controller. On comparing active suspension system with passive, it gives a high control performance for a wide frequency range, thus, it is better than passive. However, it requires high power supply, sensors and servo-valves. Therefore, it is expensive and is not used for commercial applications.
A semi-active suspension makes use of Magneto-rheological dampers in which the force is indirectly commanded through'a controlled change in damper properties. This change gets effected when the damper controller receive an information from the system controller. Semi-active suspensionk systems have advantagess of both i.e., passivee and active suspension systems. It'is more economical than active suspension system and providesf ridee comfort and vehicle stability. If there'is failure of control system than it can also work as passive suspension system. MR damper is a semi-active damper, filled with magneto rheological fluid (MRF) which changes the physical characteristics when subjected to magnetic field. Two nested controllers are necessary in semi-active suspension system incorporating with MR damper. Magnetorheological (MR) fluid is a functional fluid that changes its physical characteristics when magnetic field is applied. Magnetorheological fluids (MRFs) consist of suspended ferrous particles like carbonyl iron particles that are micron sized, and are dispersed in a carrier medium. When magnetic field is applied these suspended particles in MRF gets magnetiseds and align themselves in structures like chains which resists the shear deformation of fluid. This change in material results in a rapid increase in viscosity or in the formation of a semisolid state The first is system controller, it computes the desired damping force needed by the MR damper for achieving the given system conditions. The second is damper controller, which commands the damper to generate the desired force. This controller effectivenesss dependss on its skills to deal withtthe nonlinear hysteretic nature ofothe vehicle.

*Corresponding author: Sharma S, Department of Mechanical Engineering, Aligarh Muslim University, India, Tel: 2700920; E-mail: sidharth.9910@gmail.com

Received December 14, 2017; Accepted January 31, 2018; Published February 04, 2018

Citation: Sharma S (2018) Vibration Control in Quarter-Car Model with Magnetorheological (MR) Dampers Using Bingham Model . J Appl Mech Eng 7: 299. doi:10.4172/2168-9873.1000299

Copyright: ( 2018 Sharma S. This is an open-access article distributed under the terms of the Creative Commons Attribution License, which permits unrestricted use, distribution, and reproduction in any medium, provided the original author and source are credited. 


\section{Literature Review}

The following literature searchois conducted tok establish the existing and the past research associated with the magnetorheological damperss and vibratione control of semi-actives suspensionf system. MR damper isha special type of damper thatuis filled with magnetorheological fluid. The magneto-rheological fluidssshould be very stable whenpit comes to settling atpthe bottom and should also have a high level of magnetic saturation [2]. Also thee main point of discussion that can be considered is that the MR fluids should be highly corrosion resistant asr it handles that most vulnerable component off any automobile. Consideringe this point, many different types of magnetic material haveebeen tested by the researchers depending on its emulsions withe different carrier fluids likee the magnetic material made off the polystyrene particles with the addition of the magnetite [3], thee nano-sized fferrite particles coated with a polymer [4], mesoscalee carbonyl iron ande nickel zinc ferrite ferrite [5], iron oxide forr magnetitei $\left(\mathrm{Fe}_{3} \mathrm{O}_{4}\right)$ nanoparticles [6]. The MR dampers from theirr inventions have beene used in many industrial applications. Linear dampers [7], rotary brakes [8].

In a study att the University of Sakarya, thee experimental and thee theoretical analysis was carried out that predicted theebehavior of a linear magneto-rheological damper. A magnetorheological damper wass designed and fabricatedd for testing the dynamic behaviour on"a mechanical type shock machine which was under sinusoidal excitation. A theoretical flow analysis was done onn the prototype MR damper which was based on the Bingham plastics consecutive model and aa parametric algebra model was analyzed to check the hysteresis behaviour of the MR damper. The final observation was that the algebraic model'swas' very successful at' the highest excitation velocity of $0.2 \mathrm{~m} / \mathrm{s}$ [9].

A model MR fluid was developed using silicon oil OKS 1050 which was further diversed with the carbonyl powder. Moreover, in order to reduce the sedimentation Aerosi 200 was integerated as a stabilizer. Further, the magnetic field due to the magneto-rheological fluids was modeled by means of the finite element method. The obtained model was then analyzed with the ANSYS software and was observed that the obtainable model fully satisfied the dynamic properties of the mechanical system [10]. The performancee of the MR dampers wass built to examine and investigate the 2-D axi-symmetric MR damper. Inn these experiments, six different configurations of the MR damper piston were simulated which can give a obvious idea of the maximum pressure drop that the particular damper can provide. In additional investigation, the piston velocity and the input current to the coil were variede to assess for the magnetic flux density and the pressure drop along the damper [11].

\section{Mathematical Modelling of System}

\section{Quarter car model with passive suspension system}

A quarter car model is used in research work to study the vehicle dynamics. This model depending on the degree of simplification used by the researcher may be considered as a single (1DOF), two (2DOF) or three degree of freedom (3DOF). We are considering, two degrees of freedom for the simplicity of calculation as compared to 3 DOF. Quarter sprung and unsprung mass of the vehicle will be considered. The line diagram of the 2 DOF quarter-car model is shown in Figure 1.

The equations for this model are as follows:

$M_{s} \cdot A_{s}=-\left[\left[K_{s}\left(X_{s}-X_{u}\right)+C_{s}\left(V_{s}-V_{u}\right)\right]\right]$
$\mathrm{M}_{\mathrm{u}} \cdot \mathrm{A}_{\mathrm{u}}=\left[\mathrm{K}_{\mathrm{s}}\left(\mathrm{X}_{\mathrm{s}}-\mathrm{X}_{\mathrm{u}}\right)+\mathrm{C}_{\mathrm{s}}\left(\mathrm{V}_{\mathrm{s}}-\mathrm{V}_{\mathrm{u}}\right)\right]-\left[\mathrm{K}_{\mathrm{t}}(\mathrm{Xu}-\mathrm{q})+\mathrm{C}_{\mathrm{t}}\left(\mathrm{V}_{\mathrm{u}}-\mathrm{V}_{\mathrm{q}}\right)\right]$

Where, $M_{s}$ and $M_{u}=$ Sprung and unsprung mass of vehicle respectively,

$\mathrm{K}_{\mathrm{s}}, \mathrm{C}_{\mathrm{s}}$ and $\mathrm{K}_{\mathrm{t}}, \mathrm{C}_{\mathrm{t}}=$ Suspension system and tires parameters respectively,

\section{Quarter car model with semi-active suspension system}

The proposed design is a two degree of freedom quarter car model for semi active suspension system using MR dampers. The proposed model adapts the regularized Bingham model to accurately reproduce the hysteretic behaviour of such dampers [12]. (This method is commonly used for modelling MR damper).

Bingham model: The idealisation of the'visco-plastic MR-damper model'presented in Dyke et al. uses similarities in'the rheological behaviour of ER and MR fluids and'the similar'techniques in'the modelling' of ER dampers.

In'the rheological structure'in Figure 2 in which'the Bingham model is'based, there is'a Coulomb friction element' $f_{c}$ placed parallel to'the dashpot $\mathrm{C}_{0}$. According to Bingham's MR damper'model, for non-zero piston velocities' $\mathrm{V}$, the damping force $\mathrm{F}$ can'be expressed'as:

$$
\mathrm{F}=\text { fc. } \operatorname{sgn} \mathrm{x}^{\cdot}+\mathrm{c}_{0} \mathrm{x}^{\cdot}+\mathrm{f}_{0}
$$

where' $f c$ is'the frictional force, $c_{0}$ is'the viscous damping'parameter, $\mathrm{f}_{0}$ is'the force due to'the presence of the accumulator. This'last simplification in'the model results from'the assumption that'the elasticity replacing'the accumulator activity has'a low stiffness'and linear characteristics.

Quarter car model: The Figure 3 below demonstrates the quarter car model for semi active suspension system with MR damper and controller. Here, $M_{s}$ and $M_{u}$ are the one quarter of sprung mass and unsprung mass (wheels, spring and dampers) respectively. $\mathrm{X}_{\mathrm{s}}$ and $\mathrm{X}_{\mathrm{u}}$ are

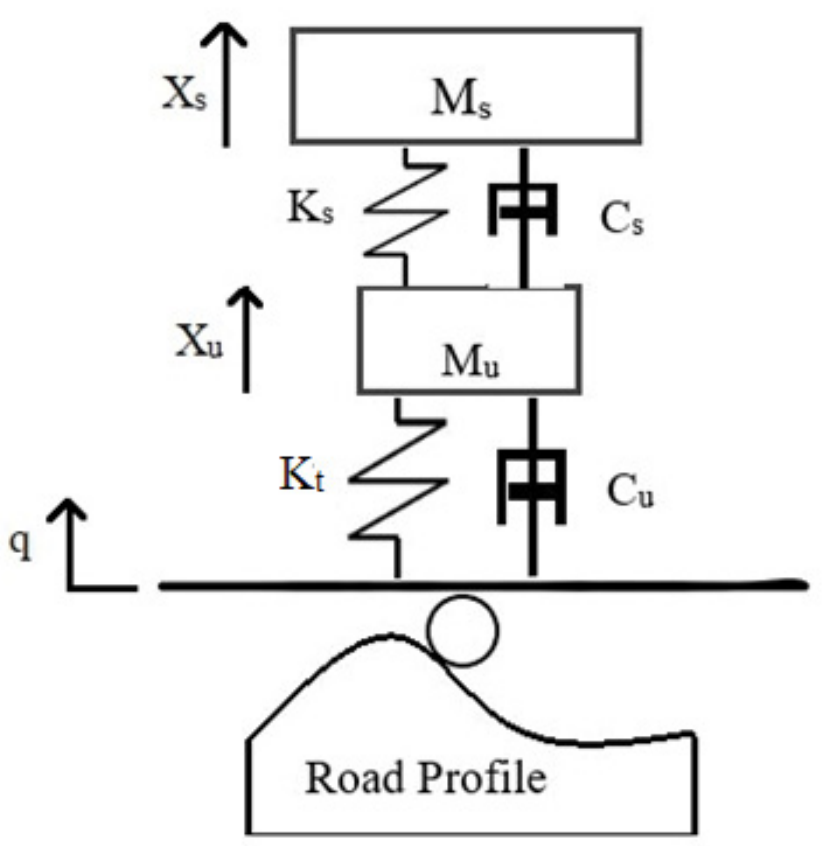

Figure 1: Quarter car model for passive suspension system. 


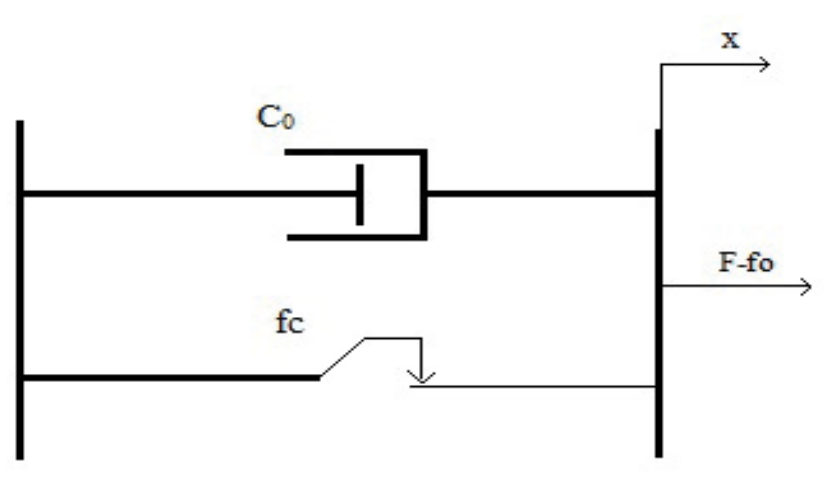

Figure 2: Rheological structure of a MR damper for the Bingham model.

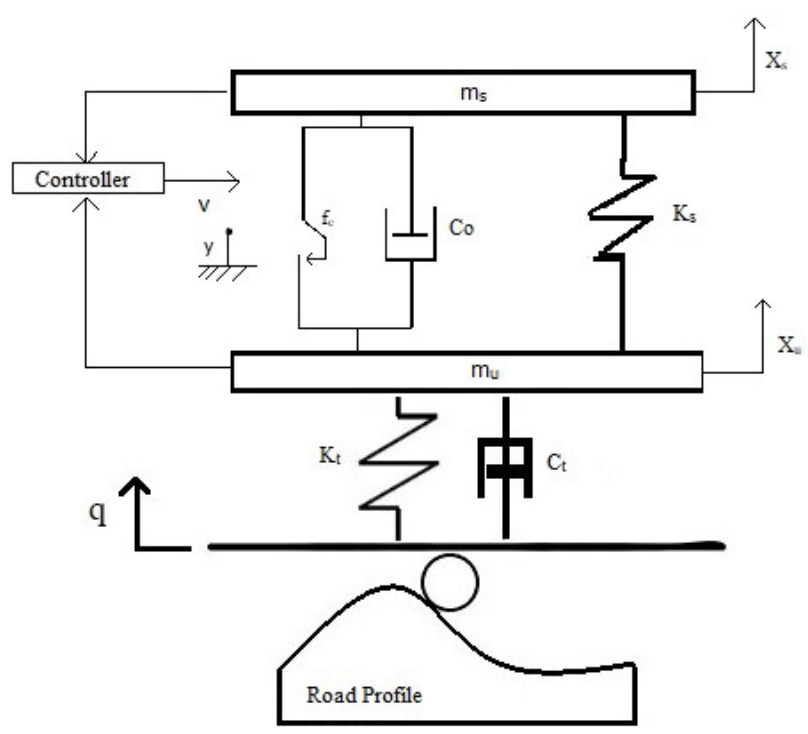

Figure 3: Vehicle quarter car model with semi active suspension system.

\begin{tabular}{|c|c|c|c|}
\hline Current & \multicolumn{3}{|c|}{ Value of parameters } \\
\hline $\mathbf{I}[\mathbf{A}]$ & $\mathbf{f}_{\mathbf{c}}[\mathbf{N}]$ & $\mathbf{C}_{0}[\mathbf{N s} / \mathbf{m}]$ & $\mathbf{f}_{0}[\mathbf{N}]$ \\
\hline 0.0 & 43.950 & 735.90 & 195.510 \\
\hline 0.4 & 262.130 & 3948.70 & 186.280 \\
\hline
\end{tabular}

Table 1: Parameters of Bingham model.

the values of displacement in masses and q"represents the disturbances caused due to change in road profile, $\mathrm{K}_{\mathrm{t}}$ is the stiffness of tires; $\mathrm{K}_{\mathrm{s}}$ is the spring"co-efficient for spring between wheel and chassis

For the system, $\mathrm{V}_{\mathrm{s}}$ and $\mathrm{V}_{\mathrm{u}}$ are the absolute velocity of sprung mass and unsprung mass respectively. The force $f_{a}$ of semi active suspension system is the function of system controller. Controller generates the required voltage $\mathrm{v}$ in the MR damper. The equations obtained from the above model for suspension system and vehicle body are as follows:

$$
\begin{aligned}
& M_{s} \cdot A_{s}=-\left[k_{s}\left(X_{s}-X_{u}\right)+f_{a}\right] \\
& M_{u} \cdot A_{u}=\left[k_{s}\left(X_{s}-X_{u}\right)+f_{a}\right]-\left[k_{t}\left(X_{u}-q\right)+C_{t}\left(V_{u}-d / d t(q)\right)\right]
\end{aligned}
$$

The design parameters for Bingham Model are taken from $[13,14]$. Table 1 shows the values of different parameters for current values.

\section{MATLAB Models}

Modeling of quarter car model for passive suspension system is done using Simulink software. Figure 4 shows Simulink model of passive suspension system.

Similarly, Semi active suspension system is modeled using Simulink and Bingham model parameters are used for MR damper modeling. Figure 5 shows the Simulink model of a semi active suspension system.

Table 2 shows values of various suspension system parameters. In order to model both the suspension systems, these parameters are taken into consideration.

We have taken a random road input to compare the acceleration of sprung mass for passive and semi active suspension system. Figure 6 below is a simulation of random road profile.

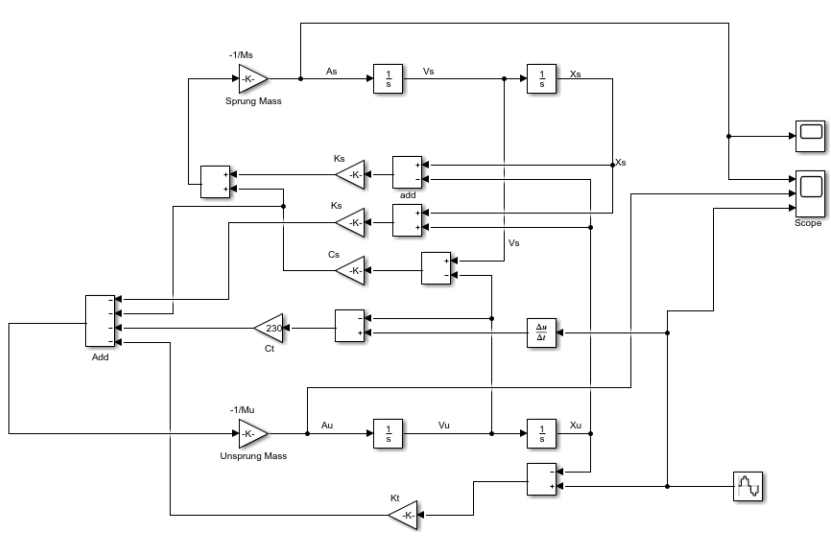

Figure 4: Simulink modeling of passive suspension system.

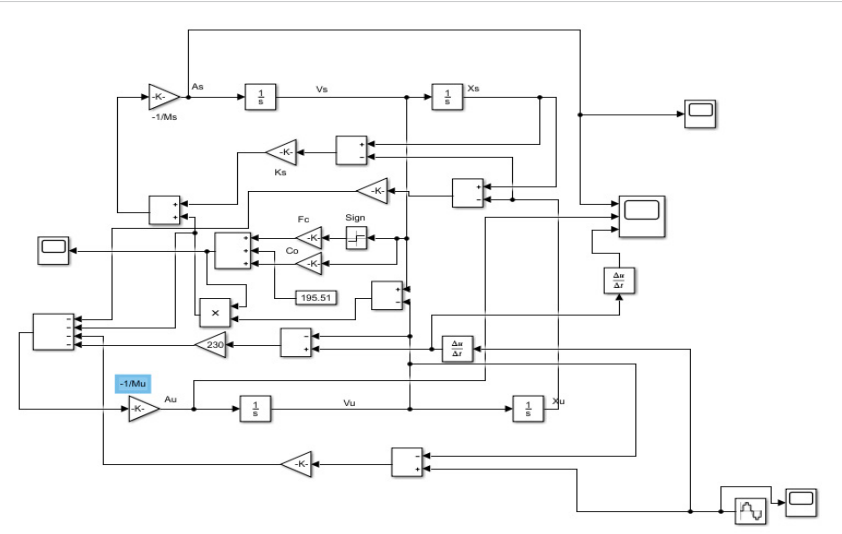

Figure 5: Simulink modeling of semi-active suspension system using Bingham model.

\begin{tabular}{|c|c|}
\hline System Parameters & Values \\
\hline Sprung Mass $\left(M_{s}\right)$ & $450 \mathrm{Kg}$ \\
\hline Unsprung Mass $\left(M_{\mathrm{u}}\right)$ & $45 \mathrm{Kg}$ \\
\hline Suspension Stiffness $\left(\mathrm{K}_{\mathrm{s}}\right)$ & $22000 \mathrm{~N} / \mathrm{m}$ \\
\hline Passive Suspension Damping coefficient $\left(\mathrm{C}_{\mathrm{s}}\right)$ & $2300 \mathrm{~N}-\mathrm{s} / \mathrm{m}$ \\
\hline Tire Stiffness $\left(\mathrm{K}_{\mathrm{t}}\right)$ & $176000 \mathrm{~N} / \mathrm{m}$ \\
\hline Tire Damping coefficient $\left(\mathrm{C}_{\mathrm{t}}\right)$ & $230 \mathrm{~N}-\mathrm{s} / \mathrm{m}$ \\
\hline
\end{tabular}

Table 2: Suspension parameters of quarter car model [14]. 


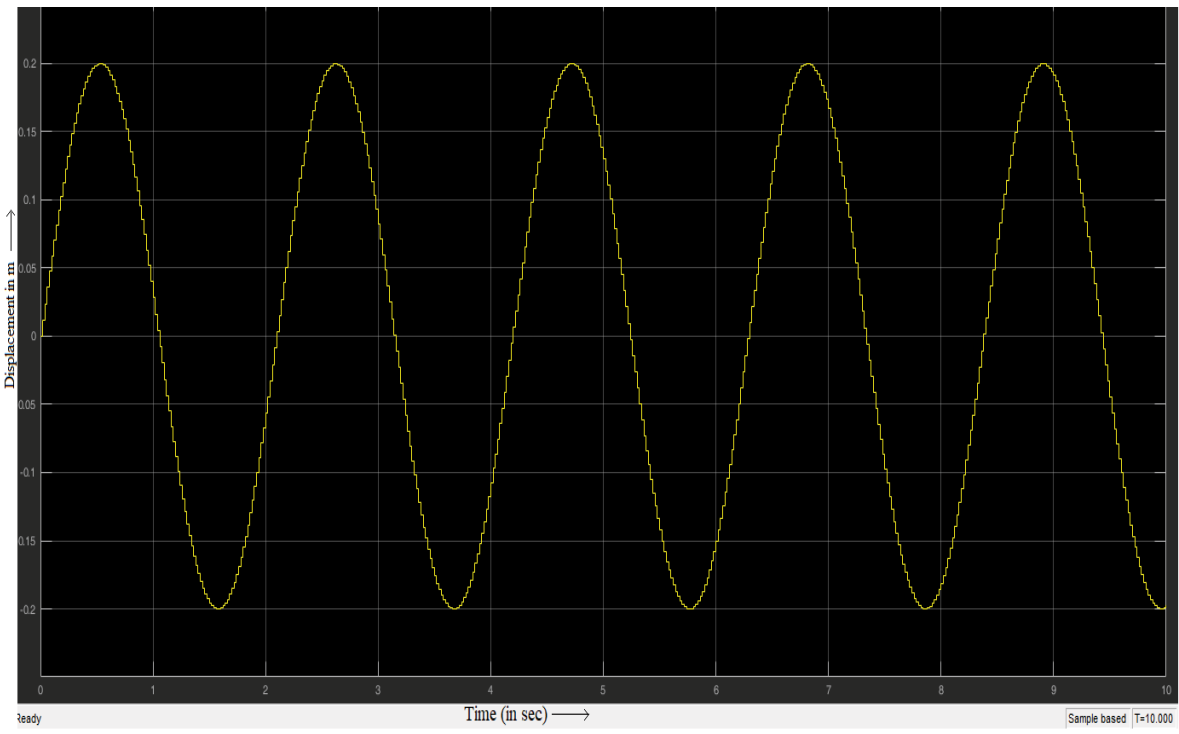

Figure 6: Random road input.

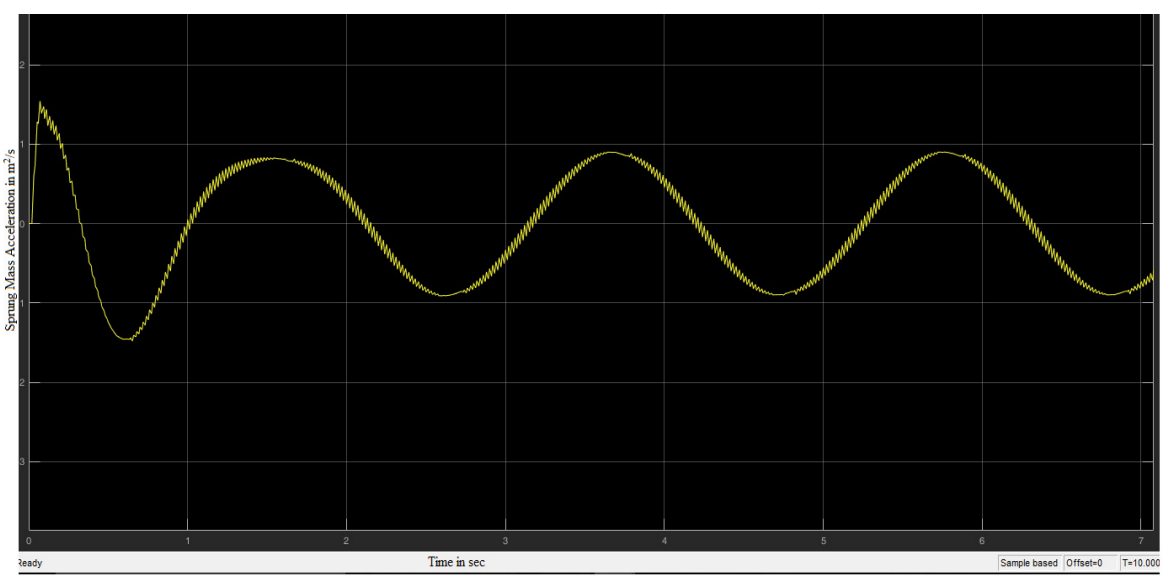

Figure 7: Sprung mass acceleration (Passive suspension) vs. time

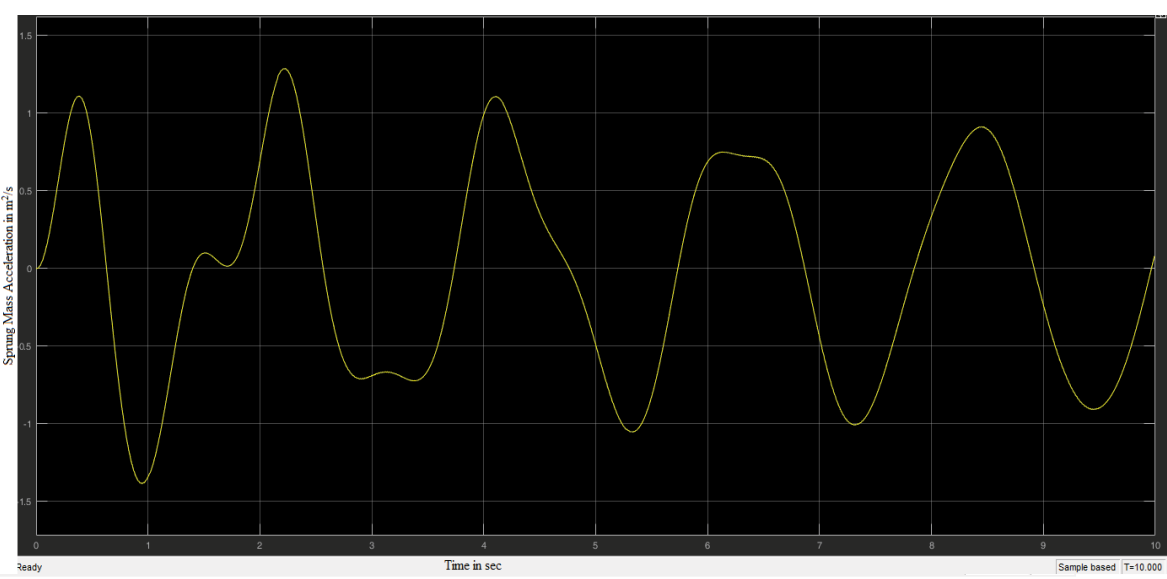

Figure 8: Sprung mass acceleration (Semi-active suspension) vs. time. 
Citation: Sharma S (2018) Vibration Control in Quarter-Car Model with Magnetorheological (MR) Dampers Using Bingham Model . J Appl Mech Eng 7: 299. doi:10.4172/2168-9873.1000299

\begin{tabular}{|c|c|}
\hline Suspension System & Sprung Mass Acceleration in $\mathbf{~} / \mathbf{s}^{\mathbf{2}}$ \\
\hline Passive suspension system & 1.55 \\
\hline Semi-active suspension system & 1.26 \\
\hline
\end{tabular}

Table 3: RMS value of sprung mass acceleration for passive and semi active system.

\section{Simulation of Results and Discussion}

Modeling of passive suspension system shows the results shown below. Figure 7 is a graph of sprung mass acceleration of passive suspension system vs. Time (s).

Figure 8 shows the result of modeling of semi active suspension system in form of graph between Sprung mass acceleration of suspension system vs Time (s).

Table 3 below shows the maximum sprung mass acceleration for passive and semi active suspension and the difference between both.

Percentage Variation $=[(1.55-1.26) \times 100] / 1.55=23.02 \%$

\section{Conclusion}

The comparison of results from Simulink modeling of passive and semi active suspension system have been done and the percentage variation in maximum sprung mass acceleration of semiactive suspension system based on Bingham model is $23.02 \%$ from passive suspension system. So it shows that semiactive suspension system gives lower value of maximum sprung mass acceleration for given random road excitation. Hence, it can be concluded after study, mathematical modeling and simulation results that suspension system with semi active suspension system gives a better vehicle stability than passive suspension system.

\section{References}

1. Yi K, Hedrick K (1993) Dynamic tire force control by semi-active suspensions. J Dynamic Systems Measurements and Control 115: 465-474.
2. Ghaffari Ali, Hashemabadi SH, Ashtiani M (2015) A review on the simulation and modeling of magnetorheological fluids. J Intelligent Material Systems 26 : 881-904.

3. Lemaire E, Bossis G, Grasselli Y (1993) Yield and stress structuration of magneto-rheological suspensions. J Magnetism and Magnetic Materials 122: $51-52$.

4. Kormann C, Laun HM, Richter HJ (1996) MR fluids with nano-sized magnetic particles. Int J Modern Phy 10: 3167-3172.

5. Phule PP, Ginder JM (1999) Synthesis and properties of novel magnetorheological fluids. Int J Modern Phy 13: 2019-2027.

6. Zafarani-Moattar M, Majdan-Cegincara R (2013) Stability, rheological magnetorheological and volumetric characterizations of polymer based magnetic Nano fluids. Colloidal and Polymer Science. 291 :1977-1987.

7. Sapinski J, Goldasz B (2012) Non-dimensional characterization of flow-mode magnetorheological/electrorheological fluid damper. J Intelligent Mater Sys and Struct 23: 1545-1562.

8. Farjoud A, Vahdati N, Fah YF (2008) Mathematical model of drum-type MR brakes using Herschel-Bulkley shear model. J Intelligent Mater Sys and Struct 19: $565-572$.

9. Sevki C, Tahsin E (2010) Modeling and testing of a field-controllable magnetorheological fluid damper. Int J Mech Sci 52: 1036-1046.

10. Kciuk S, Turczyn R, Kciuk M (2010) Experimental and numerical studies of MR damper with prototype magnetorheological fluid. J Achievements in Mater and Manufact Eng 39: 10-12.

11. Suresh A, Khan M, Sadak Ali, Seetha RN (2012) Investigation on the performance of $\mathrm{mr}$ damper with various piston configurations. Int J Scientific and Research Publications 2:12.

12. Lemaire E, Bossis G, Grasselli Y (1993) Yield and stress structuration of magneto-rheological suspensions. J Magnetism and Magnetic Mater 122: 51-52.

13. Kormann C, Laun HM, Richter HJ (1996) MR fluids with nano-sized magnetic particles. Int J Modern Phys 10: 3167-3172.

14. Phule PP, Ginder JM (1999) Synthesis and properties of novel magnetorheological fluids. Int J Modern Phy 13: 2019-2027. 